Ramon-Berjano: Hong Kong and the Pearl River Delta: The Emergence of a Super Zone

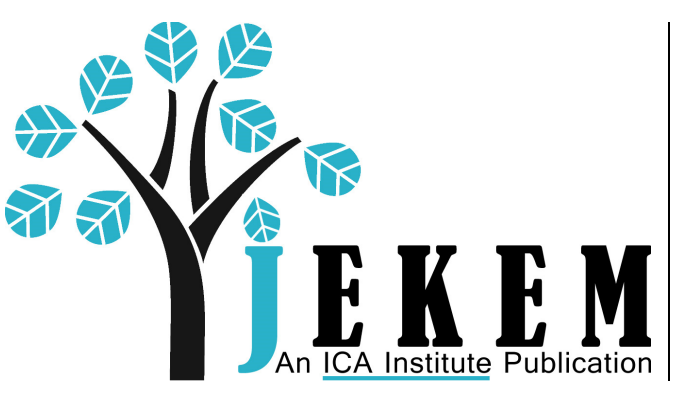

INDIA, CHINA AND AMERICA INSTITUTE

1549 Clairmont ROAD, SUITE 202 • DECATUR, GA 30033 USA

WWW.ICAINSTITUTE.ORG

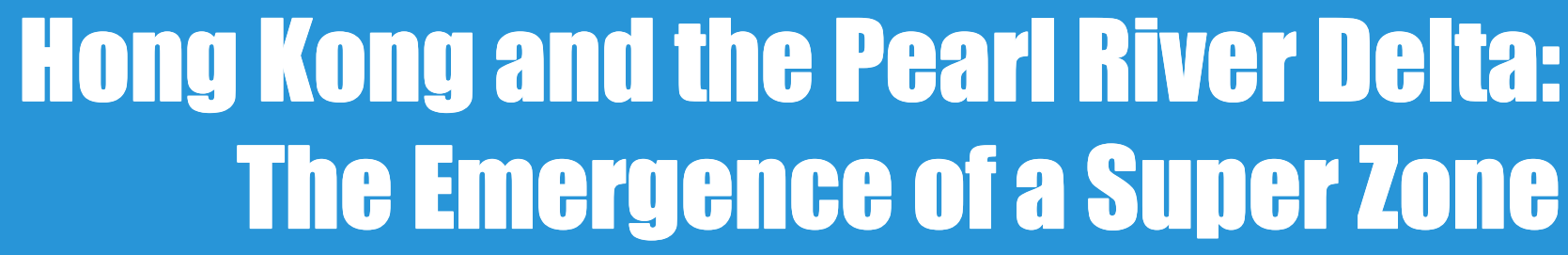

Carole B. Ramon-Berjano

Journal of Emerging Knowledge on Emerging Markets

Volume 2

November 2010

Published by DigitalCommons@Kennesaw State University, 2010

1 


\section{llong Kong and the Pearl River Delta: The Emergence of a Super Zone}

Carola B. Ramon-Berjano

University of Hong Kong

Journal of Emerging Knowledge on Emerging Markets

Volume 2

November 2010

7 he relationship between Hong Kong and Mainland China entered a new phase in the last couple of decades. Within this period, several events were crucial in transforming the region into a growth super zone, namely the opening up of the Chinese economy, the reunification of Hong Kong with mainland China and the trade agreements signed between Hong Kong and China in 2003.

In 1978, China embarked on a process of opening up of the economy and the development model that was followed stimulated the coastal areas and re-shaped the economic structure of the province of Guangdong. In just a couple of decades, Guangdong saw its economy transform from a fishing village to a manufacturing centre. Manufacturing previously done in Hong Kong relocated to this neighbouring Mainland province and economic links between the two areas began to flourish. In 1997, and after 155 years of British colonial rule, Hong Kong was reverted to Chinese sovereignty. After reunification, and for a period of fifty years, Hong Kong would not be another Chinese province but instead it became a Special Administrative Region. Under this system, Hong Kong remained a capitalist economy and retained most of its autonomy in its domestic affairs. Contrary to many gloom forecasts, reunification with Mainland China allowed the economy of Hong Kong to further strengthen its links with Guangdong province and further consolidate its position as a service hub in the region. A third aspect that determined the success of the economic super zone in the region was the signing of the Closer Economic Partnership Agreement between 


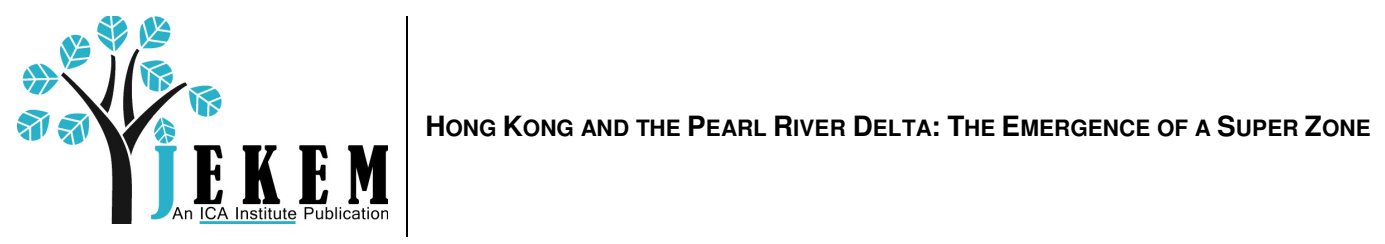

China and Hong Kong in 2003. Links between the two have increased even further since then, under the expanding framework of the agreement.

This paper discusses these three aspects underpinning the creation of the Pearl River Delta super zone in more detail. The development of Hong Kong during and after colonial times is reviewed; together with an account of the opening up process in China and the emergence of the coastal areas, in particular the province of Guangdong and the city of Shenzhen. Finally, the future of this region and the prospects for a deepening integration between Hong Kong, Guangdong and neighbouring provinces is also discussed.

\section{Hong Kong: from a barren rock to Asia's World City}

Described as a "barren rock" by a British minister in 1841, Hong Kong's economy experienced a profound transformation from its beginnings as a fishing village, to a trading port, an export oriented low-end manufacturing centre and finally to its present status as Asia's World City and international financial centre.

Following China's defeat in the First Opium War and under the Treaty of Nanking in 1842, China ceded Hong Kong to Great Britain "in perpetuity" and for the following one hundred and fifty five years it remained a British colony. Between 1842 and the onset of Second World War it was estimated that 6 million Chinese emigrated from Hong Kong. By contrast, in the fifties, and as a consequence of political developments in China ${ }^{2}$, skills and capital entered Hong Kong as well as unskilled workers in the form of Chinese refugees. Estimates calculate over a million people sought refuge in Hong Kong at that time. ${ }^{3}$ In addition, international companies formerly operating in Shanghai relocated to Hong Kong. The economy of Hong Kong thus experienced rapid growth and turned from an entrepôt trading economy to a manufacturing centre. The sixties and seventies saw Hong Kong establishing more as a labour intensive manufacturing centre with overseas exports increasing. Since the early 1980s the economy of Hong Kong grew at $6.5 \%$ annually and the economy developed and matured from a manufacturing centre to a service-based economy. With the opening of China in the late seventies, Hong Kong entrepreneurs set up their manufacturing businesses across the border in China, where land and labour were cheaper and thus manufacturing decreased in Hong Kong. At the same time, Hong Kong gained in importance as given its location and access to China provided a new role within the region as a link for trade, business and financial services with China.

Meanwhile, in 1984 the Sino-British Joint Declaration paved the way for the return of Hong Kong to Mainland China on July $1^{\text {st }} 1997 .{ }^{4}$ Initially many feared about the future of Hong Kong - leading to many Chinese emigrating from Hong Kong prior to the reunification and amidst speculation over the future economic and political future of Hong Kong. According to a magazine article in 1995 “....what's indisputably dying, though, is Hong Kong's role as a 
vibrant international commercial and financial hub home to the world's eighth-largest stock market, 500 banks from 43 nations, and the busiest container port on earth. Last year this cosmopolitan metropolis's unique blend of unfettered capitalism and minimal taxation earned it the title of "world's best city for business" in a survey of executives conducted by Fortune. But as Hong Kong becomes a captive colony of Beijing and increasingly begins to resemble just another mainland city, governed by corruption and political connections rather than the even-handed rule of law, it seems destined to become a global backwater."5

On July $1^{\text {st }} 1997$ Hong Kong became a Special Administrative Region (SAR) of the People Republic of China (PRC) for a period of 50 years under the "one country two systems" principle. ${ }^{6}$ The Basic Law, which was approved by the Chinese National People's Congress (NPC) in 1990, became Hong Kong's constitution after the handover in 1997. According to the Basic Law, while foreign affairs and defence would fall under the responsibility of the Chinese Central government; Hong Kong would preserve a significant amount of autonomy in its own customs, legal system, police force, currency, and immigration policy. In the words of President Jiang Zemin "After its return to the motherland, Hong Kong will retain the status of a free port and an international financial, trade and shipping centre while continuing to maintain and develop its economic and cultural relations with other countries, regions and relevant international organizations so that this international economic metropolis will forever be vibrant and dynamic."7

Over a decade later pessimism prior to the handover has given way to an optimistic view for the future of the SAR. Nevertheless, the first decade of the SAR was not free of complications. Following the handover, the Asian Financial Crisis plunged Hong Kong into a recession and by 2003, just as the economy was recovering, the Severe Acute Respiratory Syndrome (SARS) presented Hong Kong with yet another challenge. However, thanks to the impulse given by the proximity to the Pearl River Delta (PRD) area and under the Closer Economic Partnership Arrangement (CEPA) with China - as will be seen in more detail later - the future of the former "barren rock" looks anything but barren.

In fact, in stark contrast with the above-mentioned 1995 article, ten years after reunification, Hong Kong still boasts one of the lowest tax rates in the world ${ }^{8}$, its airport is within the top ten in the world ${ }^{9}$, ranked seventh largest maritime centre ${ }^{10}, 14^{\text {th }}$ least corrupt place ${ }^{11}$, top of the economic freedom index in $2008^{12}$ and is home to over 900 financial and banking offices. ${ }^{13}$ Hong Kong - far from becoming a global "backwater" has transformed itself into a major service hub in the region, rightfully earning its reputation as Asia's World City.

\section{The rise of Guangdong, the Pearl River Delta and Shenzhen}

After decades of isolation with the world, the process of opening up in 1978 signalled a significant moment in Chinese history. China embarked on a process of development and openness to the world markets that had few precedents in the world. The Chinese strategy 


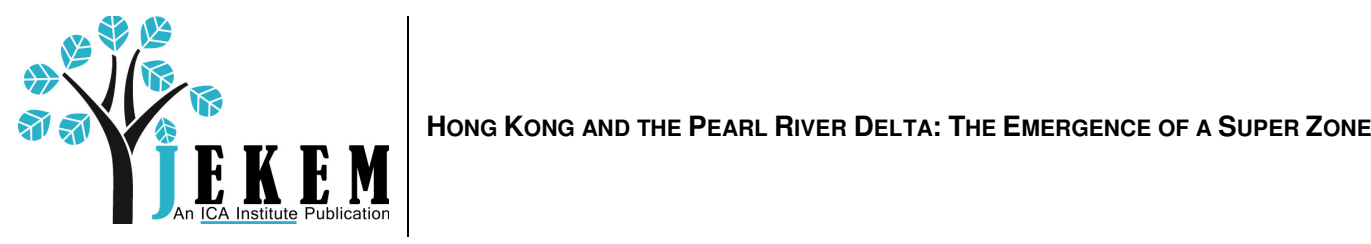

of development was conceived following the 'ladder step' doctrine, whereby different regions are different steps of a ladder. The country was divided into three zones, the coastal, central and western. ${ }^{14}$ The idea was to develop the coastal areas first - which was the highest step of the ladder, as it was generally more advanced than the other regions - and then to expand the development to the central and western areas of the country. Thus, in the early eighties, growth was led by exports and integration to the world markets, with coastal areas benefiting from easy access to ports, good infrastructure and FDI.

Four Special Economic Zones (SEZs) were created in August 1980 in the cities of Shenzhen, Zhuhai and Shantou (all three in the province of Guangdong in the South East of China) and the fourth one in the city of Xiamen, in the neighbouring province of Fujian (see map of Guangdong in the Appendix). These SEZs offered incentives in terms of tax, preferential investment, flexible employment policies, better bureaucracy and infrastructure. Although coastal areas were generally more advanced, the provinces of Guangdong and Fujian were an exception, as they had not received much investment prior to 1978. Other reasons for developing these areas were their relative small size and their proximity to Hong Kong and Macau.

On April 1984 another 14 coastal cities were also granted special policies and became 'coastal open cities'. These were Dalian (Liaoning province), Qinghuangdao (Hebei province), Yantai and Qingdao (Shandong province), Lianyungang and Nantong (Jiangsu province), Ningbo and Wenzhou (Zhejiang province), Fuzhou (Fujian province), Guangzhou and Zhanjiang (Guangdong province), Beihai (Guanxi province) and the municipalities (i.e. with provincial level status) of Tianjin and Shanghai (see map of Chinese provinces in the Appendix). The opening up continued and in 1985 three Coastal Economic Developmental Zones (CEDZs) were created, the Lower Yangtze Delta, the Xiamen-Zhangzhou-Quanzhou Triangle and the Pearl River Delta ${ }^{15}$ in the Province of Guangdong.

In 1988 Hainan Island became a separate province from Guangdong and the largest SEZ. Further, in 1990 Shanghai launched the development of the Pudong (East) New Area and was treated like a SEZ. Almost two decades later the development of East Shanghai has been so impressive that it has few parallels in the world. Other preferential zones rapidly spread, including other areas of the country. ${ }^{16}$ Yang $[1997: 31]^{17}$ mentioned a total of 422 approved special development zones as of 1995, of which 360 were in the coastal area and 36 and 26 in the central and western areas respectively. The bulk of these special areas were coastal open areas (including cities and counties) which totalled 260.

Among those areas created, the provinces of Guangdong and Fujian were most benefited and within those provinces the PRD's development as well as the city of Shenzhen's transformation from a fishing village to a major manufacturing centre was impressive. As can be seen in Figure 1, even before the reunification of Hong Kong with China; the share of Guangdong's GDP as a percentage of national GDP almost doubled in twenty years, and 
exports from Guangdong increased from under $15 \%$ to over $40 \%$ of total exports in China between 1978 and 1997.

Figure 1. GDP and Exports in Guangdong province, as Percentage of National

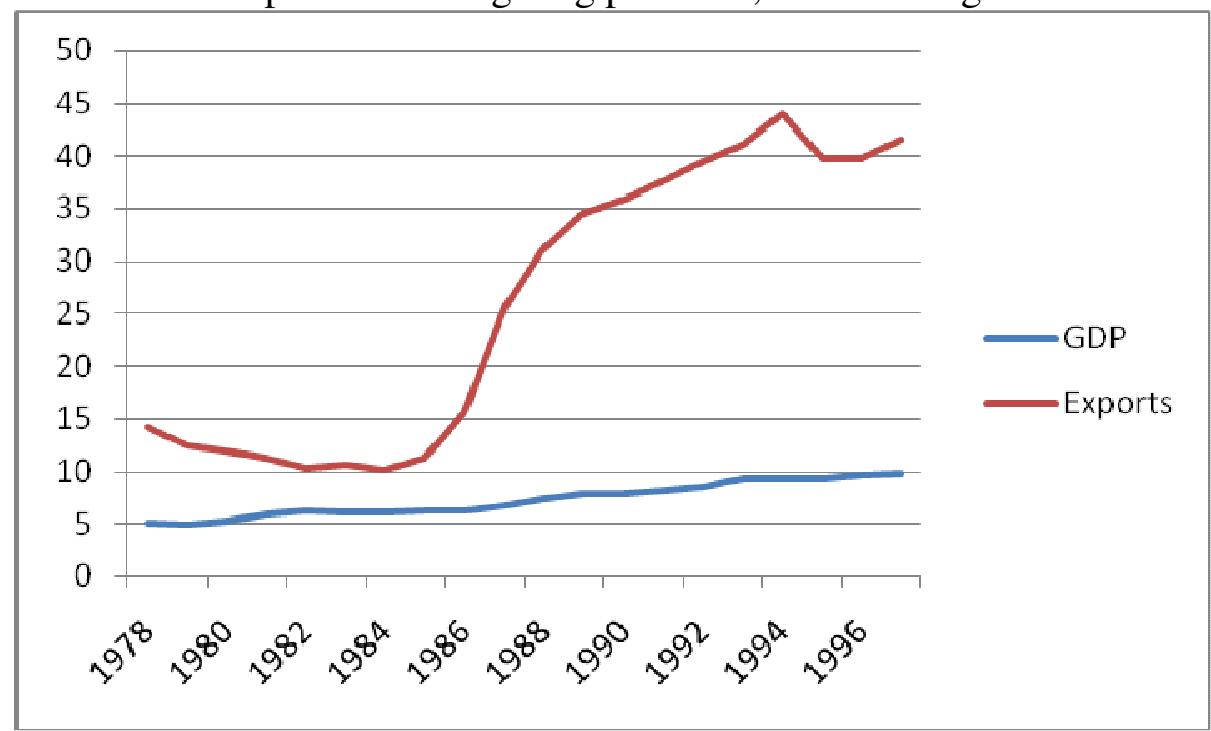

Source: "Comprehensive Statistical Data and Materials on 50 Years of New China" [1999], China Statistics Press ${ }^{18}$

As can also be seen on Table 1, while in 1978 Shanghai was the province with largest proportion of national GDP and Guangdong was number 5; by 1990 Guangdong was at the top with Shanghai at number 10. Further, in 1998, while Guangdong remained at the top with over $9 \%$ of national share of GDP; Shanghai was at number 9 - having decreased its share of national GDP from 7.86 in 1978 to 4.47 in 1998. 
Table 1. Top ten provinces in terms of national share of GDP 1978-1998

\begin{tabular}{llllll}
\hline & $\mathbf{1 9 7 8}$ & & $\mathbf{1 9 9 0}$ & & $\mathbf{1 9 9 8}$ \\
\hline Shanghai & $7.86 \%$ & Guangdong & $8.45 \%$ & Guangdong & $9.60 \%$ \\
Jiangsu & $7.18 \%$ & Shandong & $8.19 \%$ & Jiangsu & $8.73 \%$ \\
Liaoning & $6.60 \%$ & Jiangsu & $7.68 \%$ & Shandong & $8.68 \%$ \\
Shandong & $6.49 \%$ & Liaoning & $5.76 \%$ & Zhejiang & $6.05 \%$ \\
Guangdong & $5.35 \%$ & Henan & $5.07 \%$ & Henan & $5.28 \%$ \\
Sichuan & $5.32 \%$ & Zhejiang & $4.87 \%$ & Hebei & $5.16 \%$ \\
Hebei & $5.27 \%$ & Hebei & $4.86 \%$ & Liaoning & $4.71 \%$ \\
Heilongjiang & $5.03 \%$ & Sichuan & $4.83 \%$ & Hubei & $4.49 \%$ \\
Henan & $4.69 \%$ & Hubei & $4.47 \%$ & Shanghai & $4.47 \%$ \\
Hubei & $4.35 \%$ & Shanghai & $4.10 \%$ & Sichuan & $4.34 \%$ \\
\hline Source: China Stis & & & & & \\
\hline
\end{tabular}

Source: China Statistical Yearbook [several years] China Statistics Press

Within the province of Guangdong growth was not evenly distributed and the cities of the PRD grew the most, with Shenzhen and Huizhou ranking 58 and 85 (out of 94 cities within the province) in 1980 but rising to number 2 and 22 respectively in 1995. In fact, Shenzhen ranked number 2 since 1985 while Huizhou went from number 85 in 1980 to 78 in 1985, 45 in 1990 and 22 in 1995 (Jianfa et al [2000: 18]). ${ }^{19}$ According to Jianfa et al [2000:19], the most significant development in the province of Guangdong was the rise of Shenzhen in detriment of the city of Guangzhou, its capital, that went from a share of 20.90 percent of national income in 1980 to just 13.4 percent in 1995 while Shenzhen increased from 0.59 to 11.82 in that same period. He attributes this to the special economic reforms, open door policy and most importantly, the "Hong Kong factor" that contributed to the dramatic rise of Shenzhen and the relative weakening position of Guangzhou. Despite this relative shift of power in favour of Shenzhen; the process of economic concentration in the PRD area as a whole was accentuated between 1980 and 1995, with the PRD being the "single growth pole at the provincial level" (Jianfa, et al [2000: 30]).

Described as "the fastest growing portion of the fastest growing province in the fastest growing large economy in the world" (Enright, M. [2007:6] ${ }^{20}$, the importance of the Pearl River Delta cities within China can be seen in Figure 2, where the top ten cities in terms of per capita annual average disposable for 2006 is depicted. Four of the ten cities belong to the PRD region (Dongguan, Shenzhen, Guangzhou and Zhongshan) with Dongguan and Shenzhen ranking ahead of Shanghai and Beijing. 
Figure 2. Annual average per capita disposable income, top 10 cities in China, 1996

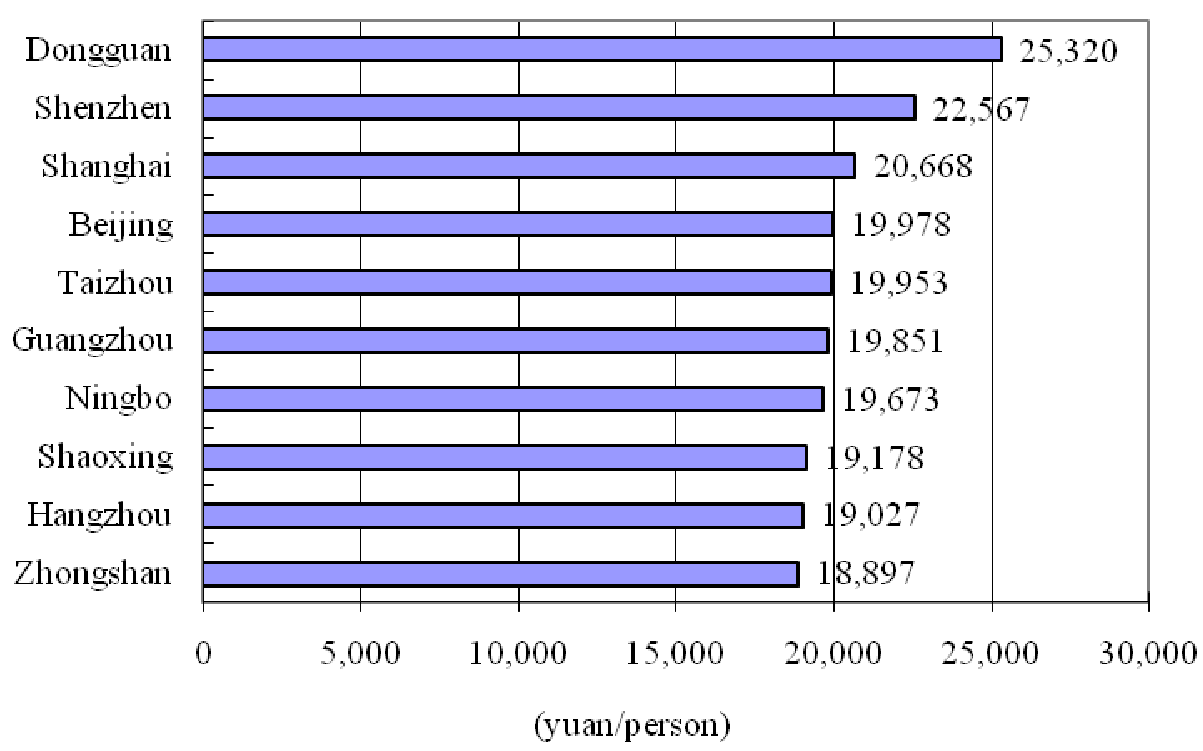

Source: China Statistical Yearbook [several years] China Statistics Press

With a permanent population of 46.34 million in 2006, the PRD comprises only a $3.5 \%$ of China's total population and a $0.4 \%$ of the land area. However, in 2006 it accounted for 10.3 percent of GDP and 28.8 percent of total trade in the country - and 82.7 and 96.2 percent of Guangdong's GDP and total trade respectively (Enright, M. [2007:8]).

\section{Greater PRD: WTO entry and CEPA}

The importance of the PRD continued to increase - from a GDP of just over US\$8 billion in 1980 to over US\$89 \$billion in 2000 and to a staggering US\$269.27 billion in 2006; at an average rate of growth of over 16 percent, well above the national 9.8 percent average. In addition, Guangdong's share of national GDP continued to increase from 9.6 in 1998 to 11.09 in 2001 and a further 11.34 percent in 2006. After Hong Kong and Macau's reunification with Mainland China in 1997 and 1999 respectively, integration between the PRD and the two SARs accelerated. The Pearl River Delta region, together with the Special Administrative Regions of Hong Kong and Macau became known as the Greater PRD. This enhanced region has become one of the fastest growing in the world and a leading manufacturing centre, with Hong Kong as a financial, management and information service 


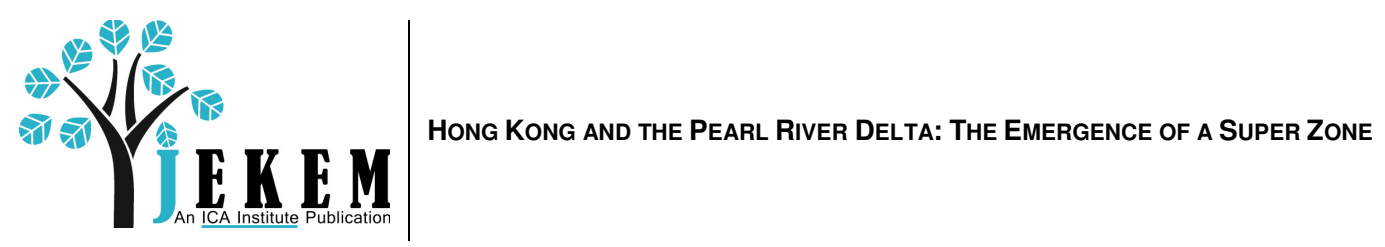

provider focal point in the region while Macau has transformed into a significant tourism destination in Asia.

The Greater PRD region received a further boost following China's into the World Trade Organisation (WTO) in 2001 and the signing of CEPA. In January 2004 the Closer Economic Partnership Agreement (CEPA) between Hong Kong and Mainland China came into effect (it was signed on June $29^{\text {th }}$ 2003). The Agreement favoured both sides, as for Mainland China it presented new business opportunities and a way of facilitating China's further integration with the world markets while for Hong Kong it provided a better access to the Mainland market. CEPA covers three main areas, namely trade in goods, services and investment facilitation.

In the original agreement, Article 3 provided for a broadening of the arrangement through constant revisions and further liberalisation. Since then, six Supplements have been signed, CEPA I (27 October 2004), CEPA II (18 October 2005), CEPA III (27 June 2006), CEPA IV (29 June 2007), CEPA V (29 July 2008) and CEPA VI (9 May 2009). Goods from Hong Kong entering China have a zero-tariff treatment which was extended in the subsequent revisions to most products while preferential access to China was also expanded to cover a wide range of service sectors. With amendments every year after CEPA was originally signed it is not surprising to see a deepening in integration within the Greater Pearl River Delta region. Figure 3 shows the GDP per city in the PRD from before Hong Kong's reunification with the Mainland in 1996 until 2007. The increase in GDP, particularly after 2003, is significant - especially for Guangzhou and Shenzhen and secondly for Foshan and Dongguan. 
Figure 3. GDP by city in PRD (in 10,000 yuan) 1996-2007.

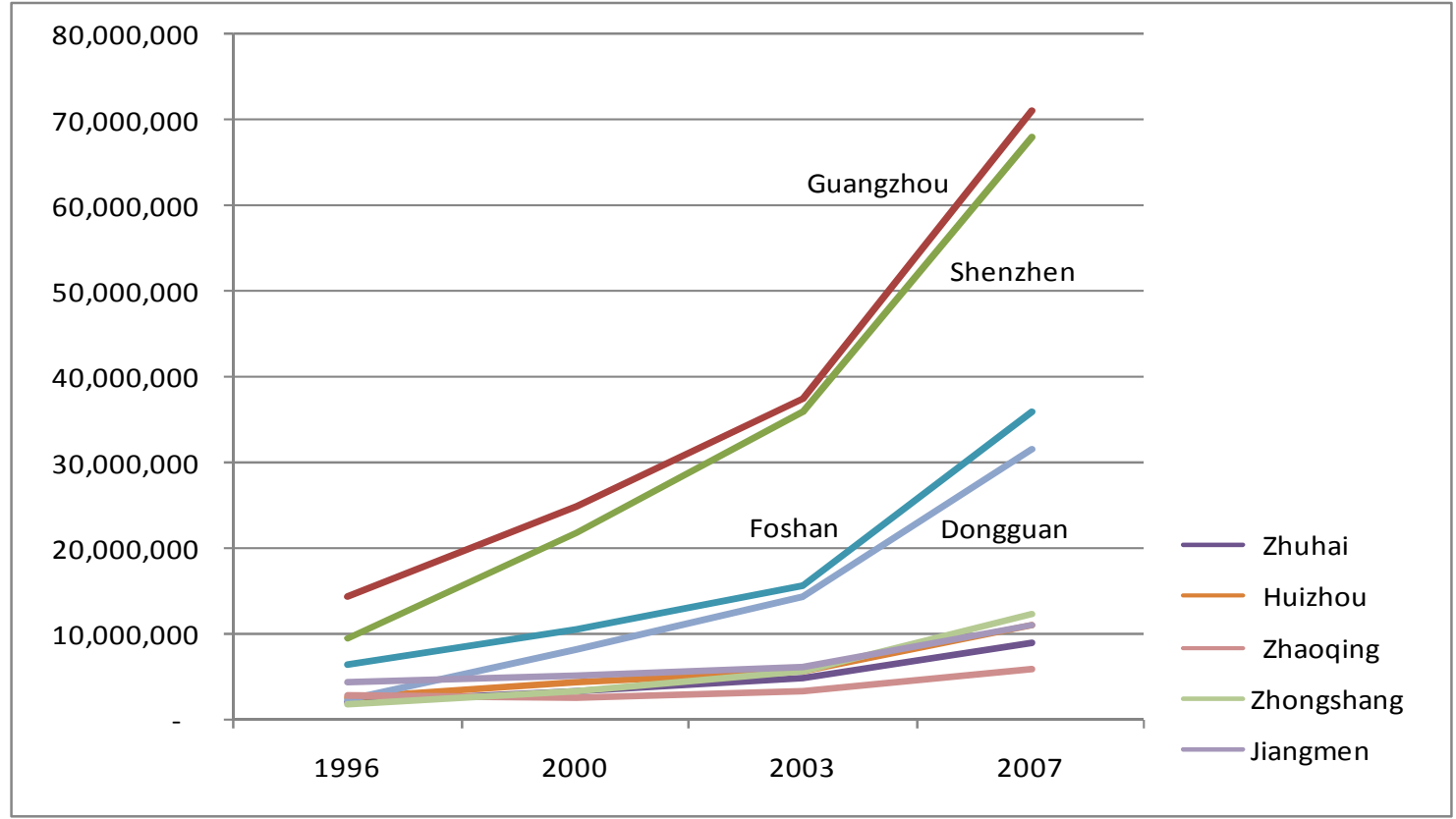

Source: China Statistical Yearbook, Guangdong Statistical Yearbook [2008], China Statistics Press.

Table 2 also shows the share of provincial GDP of the PRD cities for the same period as Figure 3. While Guangzhou maintains its share of provincial GDP, Shenzhen continues to gain share - from 14 percent in 1996 to 21 percent in 2007 - thus continuing the trend seen in the period 1980-1995, growth of Shenzhen and the relative stagnation of Guangzhou. Further, Dongguan increased its share from 4 to 10 percent; Foshan had a modest increase from 9 to 11 percent and Zhongshang a mere increase of $1 \%$. These increases in shares seem to have taken place at the expense of other cities that in the best case remained unchanged (Zhuhai) and in the worst case lost share of provincial GDP - Huizhou, Zhaoqing saw their share of provincial GDP halve and in Jiangmen it decreased by threefold. This highlights a further relocation within the PRD towards the core of the region and in particular towards Shenzhen after reunification with the Mainland. 


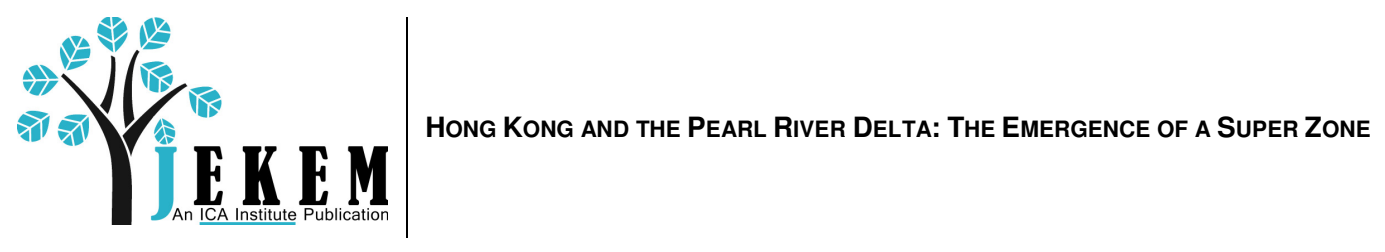

Table 2. Share of provincial GDP for the PRD cities 1996-2007

\begin{tabular}{lllll}
\hline City & $\mathbf{1 9 9 6}$ & $\mathbf{2 0 0 0}$ & $\mathbf{2 0 0 3}$ & $\mathbf{2 0 0 7}$ \\
\hline Guangzhou & 21 & 22 & 23 & 22 \\
Shenzhen & 14 & 20 & 22 & 21 \\
Zhuhai & 3 & 3 & 3 & 3 \\
Foshan & 9 & 9 & 10 & 11 \\
Dongguan & 4 & 7 & 9 & 10 \\
Huizhou & 4 & 4 & 4 & 3 \\
Zhongshang & 3 & 3 & 3 & 4 \\
Zhaoqing & 4 & 2 & 2 & 2 \\
\hline Jiangmen & 6 & 5 & 4 & 3 \\
\hline
\end{tabular}

Source: China Statistical Yearbook [several years] China Statistics Press

\section{Looking ahead: Further integration and Projects for a Pan PRD}

The creation of the SEZs and CEDZs in Guangdong in the eighties served two purposes. On the one hand it was part of a national development strategy followed by China whereby the coastal areas were given priority ahead of the central and western areas. On the other hand, the special areas in Guangdong were intended to promote the integration of the south of China with Hong Kong and Macau, and this was the key issue for the success of these special areas and the PRD. The impressive growth of China, and particularly the PRD; teamed with the international importance of Hong Kong and, most significantly, its location and position as main gateway hub into China have determined the success of the Greater PRD region. The framework given by the CEPA agreement in 2003 and subsequent additions to the agreement have allowed this area to achieve even further growth and integration. 
Table 3. Selected data, different areas ${ }^{21}$

\begin{tabular}{|c|c|c|c|c|c|c|}
\hline & China & Guangdong & $\begin{array}{l}\text { Greater } \\
\text { PRD }\end{array}$ & PRD & $\begin{array}{l}\text { Hong } \\
\text { Kong }\end{array}$ & Macau \\
\hline $\begin{array}{l}\text { Land area } \\
(\mathrm{sq} \mathbf{k m})\end{array}$ & $9,600,000$ & 179,757 & 42,648 & 41,516 & 1,104 & 29 \\
\hline $\begin{array}{l}\text { Population } \\
\text { (million) }\end{array}$ & $1,307.56$ & 91.94 & 52.79 & 46.34 & 6.84 & 0.48 \\
\hline $\begin{array}{l}\text { GDP } 2006 \\
\text { (US\$ billion) }\end{array}$ & $2,626.90$ & 325.69 & 472.32 & 269.27 & 188.76 & 14.30 \\
\hline $\begin{array}{l}\text { GDP } 2006 \\
\text { per capita US\$ }\end{array}$ & 1,714 & 3,509 & 8,947 & 5,127 & 27,527 & 28,436 \\
\hline $\begin{array}{l}\text { Real GDP } \\
\text { growth rate } \\
1980-2006\end{array}$ & $9.80 \%$ & $13.85 \%$ & $12.71 \%$ & $16.28 \%$ & $5.41 \%$ & $6.63 \%$ \\
\hline $\begin{array}{l}\text { Real GDP } \\
\text { growth rate } \\
1990-2006\end{array}$ & $10.10 \%$ & $14.51 \%$ & $11.46 \%$ & $17.34 \%$ & $4.59 \%$ & $6.37 \%$ \\
\hline $\begin{array}{l}\text { Imports } 2006 \\
\text { (US\$ billion) }\end{array}$ & 791.60 & 225.27 & 556.11 & 218.24 & 333.31 & 4.57 \\
\hline $\begin{array}{l}\text { Exports } 2006 \\
\text { (US\$ billion) }\end{array}$ & 969.10 & 301.95 & 486.29 & 288.92 & 315.52 & 2.56 \\
\hline
\end{tabular}

Source: Adapted by the author from Enright, M. [2007:25]

Thus, the last couple of decades have witnessed the emergence of a super zone comprising the PRD, Hong Kong and Macau and, within this super zone, the rise of the Shenzhen-Hong Kong megalopolis at its core. Far from reaching its peak growth, this super zone continues to tighten its integration by fostering better links between its cities, such as the Hong KongMacau- Zhuhai bridge ${ }^{22}$ - projected to be completed by 2016 - which will reduce distances between the cities considerably. Additionally, there is a proposal by Guangdong province about creating a Pan PRD with eight neighbouring provinces and the two SARs. This would include Guangdong, Fujian, Jiangxi, Hunan, Guangxi, Hainan, Sichuan, Guizhou, Yunnan, Hong Kong SAR and Macau SAR. Therefore, the potential for the Greater PRD area, with Shenzhen-Hong Kong at its core, is remains significant. 


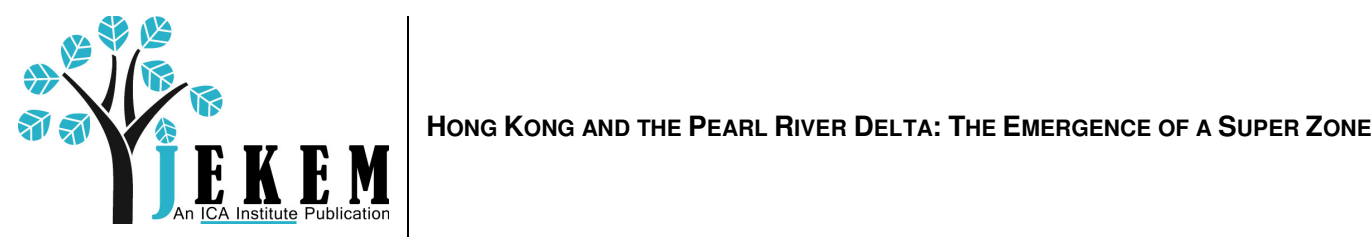

\section{Notes and References}

1. The Treaty of Nanking ceded Hong Kong Island while the Kowloon Peninsula was ceded by the Convention of Beijing in 1860 (following the Second Opium War) and the New Territories were ceded for 99 years after the Second Convention of Beijing on July $1^{\text {st }} 1898$.

2. The People's Republic of China (PRC) was proclaimed by Mao Zedong on October $1^{\text {st }} 1949$.

3. Migration data from Asia Pacific Migration Research Network (APMRN), Migration Issues in the Asia Pacific, Issues Paper From Hong Kong, UNESCO. http://www.unesco.org/most/apmrnwp7.htm

4. Although never officially repudiating the 1842,1860 and 1898 treaties, China always regarded them as "unequal" and refused to recognise its validity. China always claimed Hong Kong was part of Chinese territory and that British occupation was only temporary. At the end of the "lease" on the New Territories, Hong Kong was returned to Chinese jurisdiction. The negotiations between the United Kingdom and China over this issue are outside the scope of this paper.

5. Kraar, L. "The Death of Hong Kong", Fortune Magazine, June $26^{\text {th }} 1995$, http://money.cnn.com/magazines/fortune/fortune_archive/1995/06/26/203948/index $\underline{\text { htm }}$

6. The "one country two systems" principle was a phrase coined by Deng Xiaoping in the early eighties for potential reunification of Mainland China with Hong Kong, Macau and Taiwan. While Hong Kong and Macau (former Portuguese colony) became SAR in 1997 and 1999 respectively Taiwan has declared it has no intention to become an area of China. The crucial element of the SARs was the granting of a period of 50 years, whereby the pre-existing capitalist system would be preserved.

7. President Jiang Zemin's Speech at Ceremony for Establishment of HKSAR July 1, 1997, Ministry of Foreign Affairs of the PRC.

8. With corporate tax at $17.5 \%$ and individual taxes between 2 and $17 \%$ and no VAT (updated data for 2007)

9. With 85 airlines providing flight services with more than 150 cities worldwide and ranking number 1 and number 5 worldwide in terms of international freight and international passengers respectively in 2006 with 3.58 million tonnes of air cargo and 44.45 million passengers.

10. With 80 international shipping lines and an average of 500 weekly sailings to 500 worldwide destinations totalling 23.5 million TEUs (20-foot container units) in 2006. 
11. According to the 2007 Corruption Perception Index by Transparency International

12. Economic Freedom Index 2008, Heritage Foundation

13. With 113 Regional Headquarters, 298 Regional Offices and 518 Local Offices in Hong Kong in the Finance and Banking sector, data from the Report on 2007 Annual Survey of Companies in Hong Kong representing parent companies located outside Hong Kong, Hong Kong Census and Statistics Department (www.censtatd.gov.hk/)

14. Western Region, comprising Yunnan, Sichuan, the municipality of Chongqing, Guizhou, Shaanxi, Ningxia, Gansu, Qinghai, Xinjiang and Tibet. Central Region includes Hunan, Hubei, Jiangxi, Anhui, Henan, Shanxi, Jilin, Heilongjiang and Inner Mongolia. Belonging to the Coastal Region are Guanxi, Guangdong, Hainan, Fujian, Zhejiang, Shanghai, Jiangsu, Shandong, Hebei, Tianjin, Beijing, Liaoning.

15. The PRD is an area located in the centre-south of the province of Guangdong and includes nine prefectures (cities): Guangzhou, Shenzhen, Zhuhai, Dongguan, Zhongshan, Foshan, Huizhou, Jiangmen and Zhaoqing.

16. Alongside SEZs, CEDZs and Coastal open cities, Coastal open areas, River Valley open areas, Border region open areas, open provincial capitals, high and new technology industrial development zones, economic and technological development zones, free trade zones, and state tourist vacation zones were created.

17. Yang, D. Beyond Beijing, Liberalisation and the regions in China, Routledge Studies in China Transition, 2007.

18. Figures and tables on this paper used data from China Statistical Yearbook [several years], Comprehensive Statistical Data and Materials on 50 Years of New China [1999] and Guangdong Statistical Yearbook [2008] from China Statistics Press and Census and Statistics Department, Hong Kong SAR.

19. Jianfa, S., Gu, C., Zhen, F. and Wong, K., "Regional Polarization in Guangdong Province in South China", Occasional Paper No 113, Hong Kong Institute of AsiaPacific Studies, The Chinese University of Hong Kong (1-44), November 2000.

20. Enright, M. and Associates, "The Greater Pearl River Delta”, Invest Hong Kong, The Government of Hong Kong (1-81), 2007.

21. The table is an extract of the figures presented by Enright [2007:25-26]. All data was obtained from official figures and Statistical Yearbooks. The following notes are relevant to the information presented here. Population data refers to permanent population in the PRC and actual population in Hong Kong and Macau. Per capita GDP are all from official figures and PRD and China figures are for 2005. Real GDP growth rates, imports and exports for the Greater PRD were added figures for Hong Kong, Macau and PRD and include intra regional trade. 


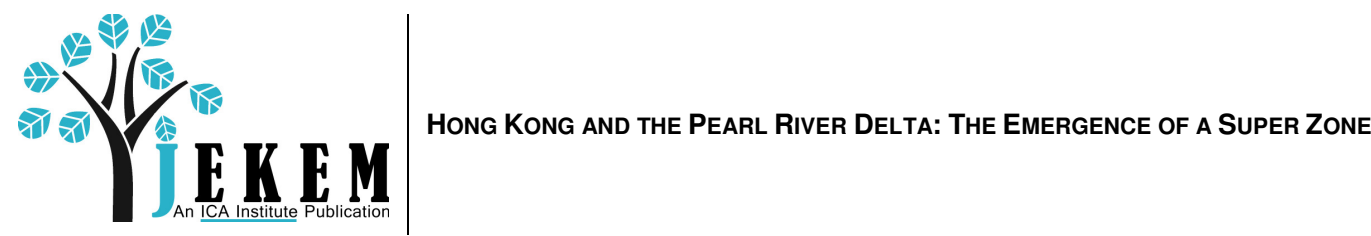

22. Construction of the 30-kilometre Hong Kong-Zhuhai-Macau Bridge is projected to begin by 2010 and it comprises bridges and tunnels linking all three areas in the western side of the PRD considerably reducing driving times between cities. 


\section{Map of China - Provinces}

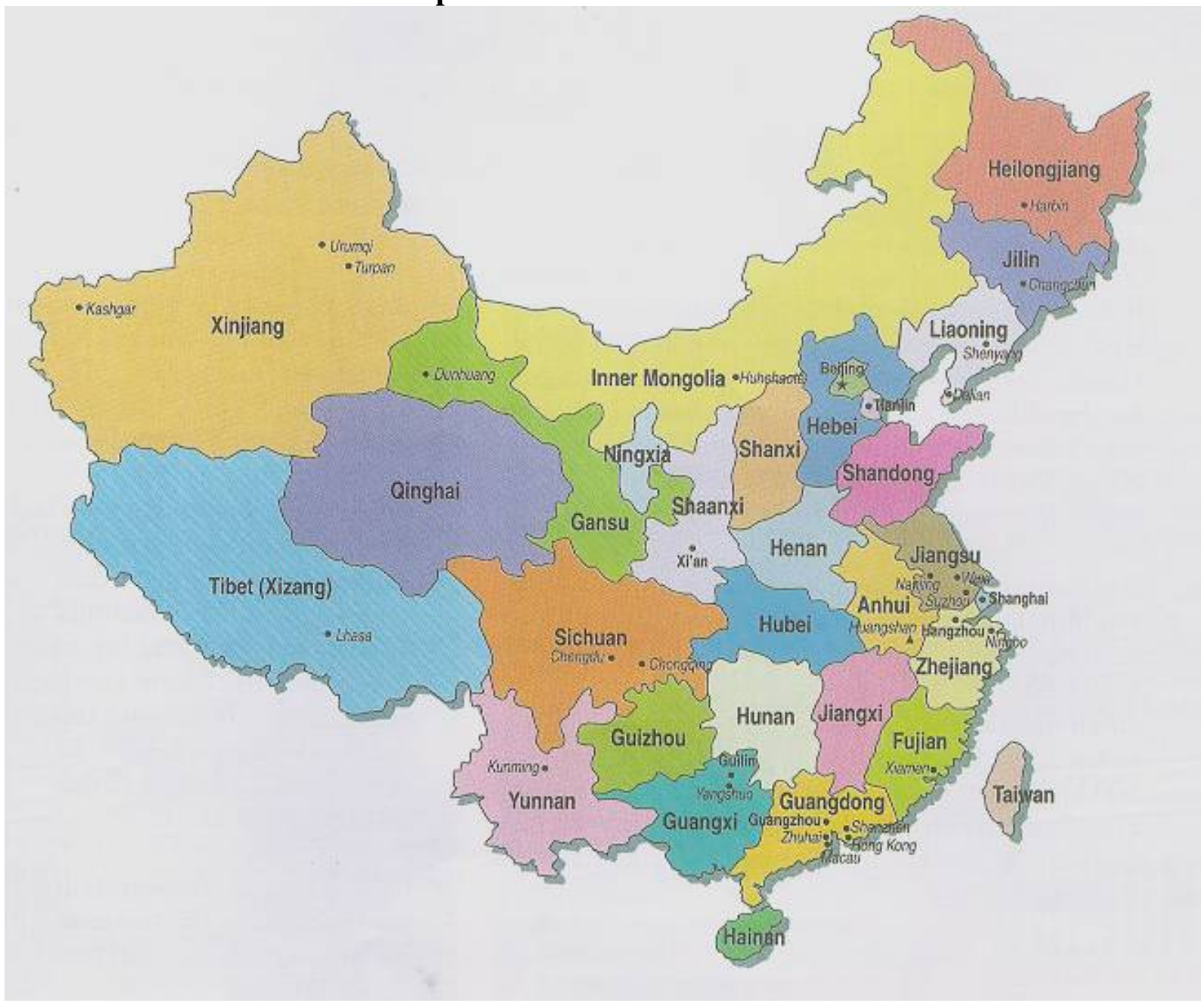

Source: http://xhes.com/v1024/images\%5Cprovinces.jpg 


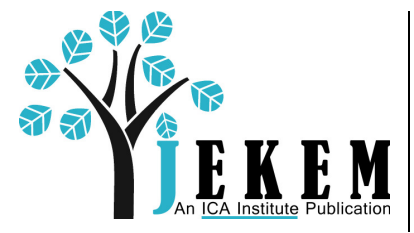

Hong Kong and the Pearl River Delta: The Emergence of a Super Zone

\section{Map of Guangdong Province}

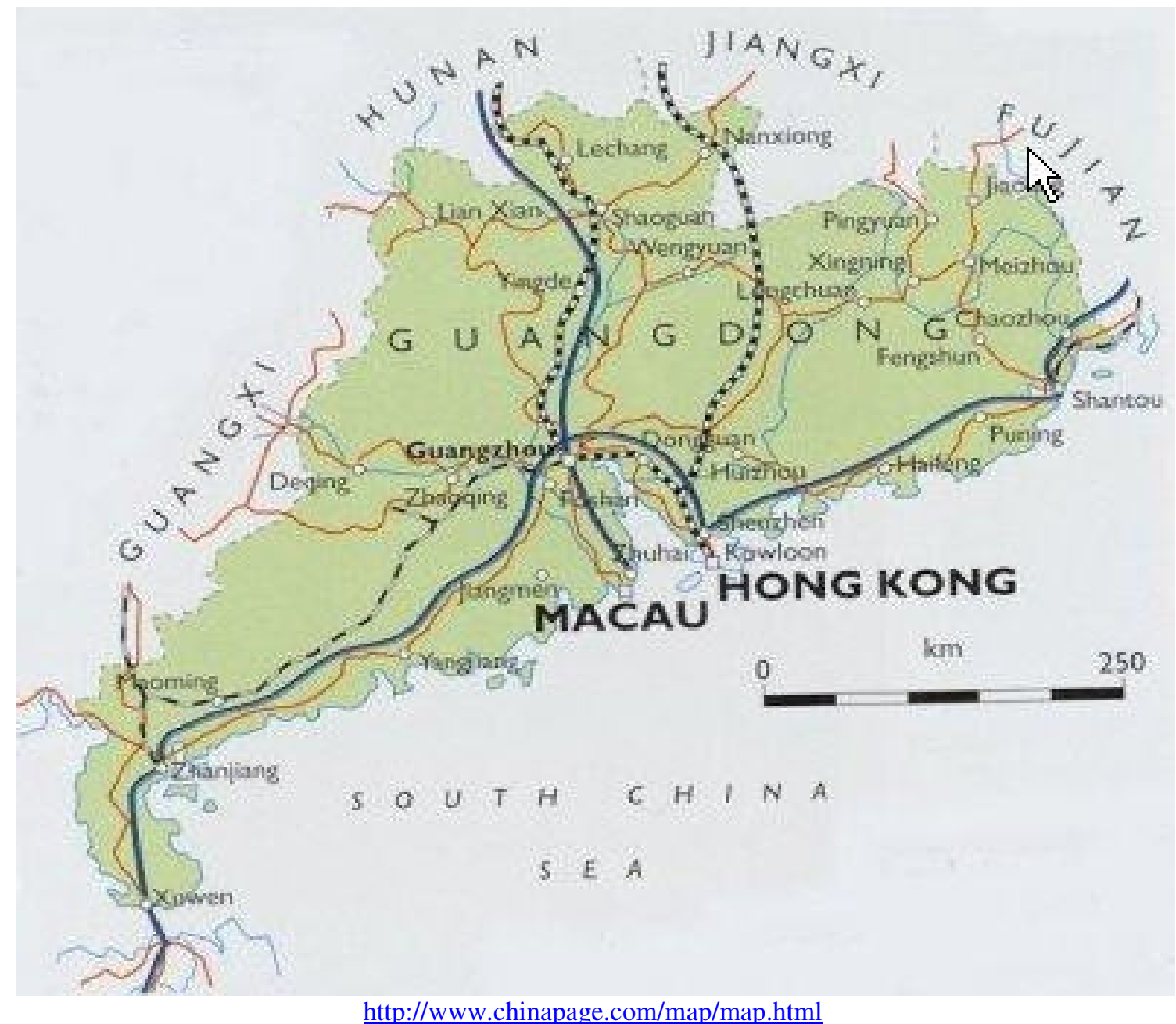

